\title{
Reappraisal of twinning: epidemiology and outcome in the early neonatal period
}

\author{
Priyanka Gupta ${ }^{1}$, MD, Mohammad Moonis Akbar Faridi $^{1}$, MD, Neerja Goel${ }^{2}$, MD, Zeashan Zaidi ${ }^{3}$, MSc
}

\begin{abstract}
INTRODUCTION The present study aimed to determine the epidemiology, maternal complications and adverse neonatal outcomes associated with twin births at a tertiary care hospital in India.

METHODS A prospective observational study was conducted on all successively born twin pairs ( $\geq 23$ weeks of gestation) and their mothers from January to September 2005. Main outcome measures included maternal medical/obstetric complications, labour characteristics and the morbidities/mortality observed during the early neonatal period.

RESULTS The twinning rate was 1 in 54 deliveries. Around $10 \%$ of mothers had a predisposition for twinning in the form of familial tendency or consumption of clomiphene. Anaemia (85\%) was the most common maternal complication, followed by gestational hypertension (17\%). Nearly one-third of births were delivered via Caesarean section. Prematurity (61\%) was the most common neonatal complication followed by early-onset neonatal sepsis (21\%). The risk of early neonatal death was $27 \%$. Shorter gestation and low birth weight were significantly associated with adverse neonatal outcome $(p<0.05)$. Factors such as chorionicity, mode of delivery, birth order, inter-twin delivery time interval, gender and intra-pair birth weight discordance did not affect neonatal morbidity or mortality $(p \geq 0.05)$.

CONCLUSION The rates of maternal complications and early neonatal morbidities/mortality were quite high in twin gestations. Except for the prematurity and low birth weight, none of the other factors, including inter-twin delivery time interval of more than 15 mins, were found to affect neonatal outcome.
\end{abstract}

Keywords: inter-twin delivery time interval, morbidities, mortality, twins

\section{INTRODUCTION}

Multiple births have fascinated mankind since the beginning of time. Twinning rates are known to show wide variations among people of various ethnicities and regions. ${ }^{(1,2)}$ Studies from other parts of the world suggest that twin gestations are associated with higher incidences of maternal, fetal and neonatal complications. For instance, besides a higher incidence of prematurity and low birth weight (birth weight $<2,500 \mathrm{~g}$ ) in twins, many other factors such as placentation (chorionicity), fetal presentation, route of delivery, inter-twin delivery time interval, birth order and gender have been reported to influence neonatal outcome. ${ }^{(3-32)}$ However, data related to twins born in the Southeast Asian region is generally lacking. The present study was designed to determine the clinico-epidemiological profile, maternal complications, labour characteristics and neonatal outcome of twin deliveries at a tertiary care hospital in India.

\section{METHODS}

A prospective observational study was performed from January to September 2005 at a tertiary care hospital in New Delhi, India, following approval from the institutional ethics committee. All successively delivered twin pairs ( $\geq 23$ weeks at the time of birth; $n=133$ ) were enrolled in the study after informed parental consent was obtained.

Data regarding maternal age, date of last menstrual period, gravida/parity status, history of twinning in the parental families, use of ovulation induction drugs and maternal medical/ obstetrics complications were noted. Details collected during labour included colour of amniotic fluid, mode of delivery, fetal presentation at the time of birth and inter-twin delivery time interval. Vigilant cardiotocographic fetal heart monitoring was conducted during labour. Outlet forceps and vacuum were applied, whenever required. The required resuscitation measures, Apgar scores at $1 \mathrm{~min}$ and 5 mins after birth, gender and birth weight were recorded for all twin infants.

Gestational age (based on date of last menstrual period) was correlated with the New Ballard Score Maturational Assessment of Gestational Age. ${ }^{(33)}$ For patients in whom age discrepancy was greater than two weeks, gestational age as per the New Ballard Score was taken into account. Intrauterine growth restriction (IUGR) was considered when the birth weight was below the 10th percentile for gestational age. ${ }^{(34)}$ Birth weight discordance (BWD) was calculated in terms of the intra-pair difference in birth weights and expressed as a percentage of the larger twin's weight. Gross and histopathological examinations of placentae were performed by a pathologist for all like-sexed pairs. Zygosity could be determined in 110 twin pairs on the basis of phenotypic gender, placental morphology and the seven blood group phenotypes. ${ }^{(35)}$

All twin neonates were admitted for the first seven days of life and bedded-in with the mother. If medically indicated, they were managed in the neonatal intensive care unit. Breastfeeding/ breast milk feeding was initiated as soon as the medical condition permitted. All morbidities and early neonatal mortality (ENNM) observed were recorded.

${ }^{1}$ Division of Neonatology, Department of Paediatrics, ${ }^{2}$ Obstetrics and Gynaecology, University College of Medical Sciences, Delhi, ${ }^{3}$ Department of Biostatistics, Era's Lucknow Medical College, Uttar Pradesh, India

Correspondence: Dr Priyanka Gupta, WZ-D/14-15, Dayal Sir Road, Uttam Nagar, New Delhi 110059, India. drpriyankaguptakapil@gmail.com 
Data was compiled and analysed using the Statistical Package for the Social Sciences for Windows version 13.0 (SPSS Inc, Chicago, IL, USA) using descriptive statistics. Neonatal morbidities and ENNM were correlated with potential factors such as chorionicity, gestational age, fetal presentation at birth, route of delivery, birth order, inter-twin delivery time interval, gender, birth weight, BWD and IUGR using Pearson's chi-square test, Fisher's exact test and logistic regression analysis.

\section{RESULTS}

Among 7,147 deliveries (gestation $\geq 23$ weeks) during the study period, 133 were twins. The rate of twinning was 1 in 54 deliveries $(133 / 7,147)$. Mean maternal age was $26.0 \pm 4.3$ (range 19-49) years and $33 \%$ of mothers were primigravidae. Family history of twinning in a first-degree relative on the mother's side was present in about $5 \%(7 / 133)$ of the women. Nearly $5 \%$ (6/133) of mothers had conceived following the consumption of clomiphene for infertility (ovulation-induction therapy) (Table I).

Anaemia during pregnancy (haemoglobin $<11 \mathrm{~g} / \mathrm{dL}$ ) was highly prevalent (85\%) in mothers of twins. Gestational hypertension (blood pressure $\geq 140 / 90 \mathrm{mmHg}$ diagnosed for the first time during pregnancy) developed in $17.3 \%$ of mothers. Among 23 mothers with gestational hypertension, 18 had preeclampsia or developed albuminuria along with hypertension. However, none of the mothers had eclampsia. Other complications included polyhydramnios (1.5\%), prelabour rupture of the membranes $(1.5 \%)$, antepartum haemorrhage $(0.7 \%)$ and oligohydramnios $(0.7 \%)$. None of the mothers developed gestational diabetes mellitus (Table I).

Mode of delivery was vaginal-vaginal in $96(72.2 \%)$ mothers and caesarean-caesarean in 36 (27.1\%) mothers. One woman was referred in after vaginal delivery of the first twin, with a retained intrauterine dead co-twin; the uterine contents of this patient were evacuated by Caesarean section. Overall, Caesarean sections were performed for $37(27.8 \%)$ mothers, and the most common indication for Caesarean section was breech first twin (27 women). All Caesarean sections were performed under spinal anaesthesia. Epidural analgesia was not provided to any woman and no internal/external podalic version was done. The most common combination of fetal presentation at birth among the twin pairs was cephalic-cephalic ( $\mathrm{n}=65,48.9 \%$ ), followed by cephalic-breech $(n=35,26.3 \%)$, breech-breech $(n=24,18.0 \%)$ and breech-cephalic $(n=9,6.8 \%)$. Excluding the one woman who was referred in, the time interval between the births of the first and second twins ranged from 1 to 60 mins (Table I).

In the present study, 51 twin pairs were unlike-sexed pairs in whom the placentation was dichorionic. Among the remaining 81 like-sexed pairs, 66 had dichorionic-diamniotic placentae and 16 had monochorionic-diamniotic placentae. In all, 117 (88.0\%) of the 133 twin gestations in our study were dichorionic, while 16 (12.0\%) were monochorionic. No monochorionic-monoamniotic placenta or conjoined twins were noted. Among the 110 twin pairs in which zygosity could be determined, 81 (74\%) were dizygotic and $29(26 \%)$ were monozygotic twin pairs, indicating a dizygotic-tomonozygotic twin ratio of 2.8:1.0 (Table II).
Table I. Maternal and labour characteristics in twin gestations ( $n=133$ ).

\begin{tabular}{|c|c|}
\hline Variable & No. (\%) \\
\hline Age* (yrs) $^{*}$ & $26.0 \pm 4.3(19-49)$ \\
\hline \multicolumn{2}{|l|}{ Gravida status } \\
\hline Primigravida & $44(33.1)$ \\
\hline Multigravida & 89 (66.9) \\
\hline \multicolumn{2}{|l|}{ Risk factor for twinning } \\
\hline Family history of twinning & $7(5.3)$ \\
\hline Clomiphene consumption & $6(4.5)$ \\
\hline \multicolumn{2}{|l|}{ Morbidities } \\
\hline Anaemia & $113(85.0)$ \\
\hline Gestational hypertension & $23(17.3)$ \\
\hline Gestational diabetes mellitus & $0(0)$ \\
\hline \multicolumn{2}{|l|}{ Amniotic fluid disturbance } \\
\hline Polyhydramnios & $2(1.5)$ \\
\hline Oligohydramnios & $1(0.7)$ \\
\hline Antepartum haemorrhage & $1(0.7)$ \\
\hline Prelabour rupture of membranes & $2(1.5)$ \\
\hline \multicolumn{2}{|l|}{ Mode of delivery } \\
\hline Vaginal-vaginal & $96(72.2)$ \\
\hline Caesarean-caesarean & $36(27.1)$ \\
\hline Vaginal-caesarean & $1(0.7)$ \\
\hline \multicolumn{2}{|l|}{ Fetal presentation at birth } \\
\hline Cephalic-cephalic & $65(48.9)$ \\
\hline Cephalic-breech & $35(26.3)$ \\
\hline Breech-breech & $24(18.0)$ \\
\hline Breech-cephalic & $9(6.8)$ \\
\hline $\begin{array}{l}\text { Inter-twin delivery time } \\
\text { interval }{ }^{+} \text {(mins) (range) }\end{array}$ & $1-60$ \\
\hline
\end{tabular}

*Data is presented as mean \pm standard deviation (range). ${ }^{\dagger}$ Total number of gestations with available data is 132 .

\section{Table II. Fetal characteristics in twin gestations $(n=133)$.}

\begin{tabular}{lr}
\hline Variable & No. (\%) \\
\hline Placentation & $117(88.0)$ \\
$\quad$ Dichorionic & $16(12.0)$ \\
Monochorionic & \\
Zygosity (n = 110)* & $81(73.6)$ \\
$\quad$ Dizygotic & $29(26.4)$ \\
Monozygotic & \\
Gender combination (n = 132)+ & $81(61.4)$ \\
Like-sexed pairs & $51(38.6)$ \\
Unlike-sexed pairs & \\
Gestational maturity at birth (wks) & $52(39.1)$ \\
$\geq 37$ & $81(60.9)$ \\
$<37$ & $13(4.9)$ \\
\hline $\begin{array}{l}\text { Antepartum or fetal death } \mathbf{2} \\
\text { gestation) [n }=\mathbf{2 6 6} \text { wks of }\end{array}$
\end{tabular}

*Zygosity could be determined in only 110 pairs. ${ }^{\dagger}$ The sex of one baby, being an acardiac twin, was unknown.

Out of the 133 twin pregnancies, 81 (60.9\%) ended in preterm deliveries before 37 completed weeks of gestation. Antepartum or fetal death ( $\geq 23$ weeks of gestation) was seen in $4.9 \%$ of twin fetuses - intrauterine death of one twin was seen 
in nine pairs and antepartum death of both twins was seen in two pairs (Table II).

Among the 253 live-born twin infants, the incidence of low Apgar score of $<7$ at $1 \mathrm{~min}$ and 5 mins of life was $7.9 \%$ and $4.3 \%$, respectively. Active resuscitation measures were required in $30(11.9 \%)$ infants - $28(11.1 \%)$ infants received positive pressure ventilation alone, and $2(0.8 \%)$ required both positive pressure ventilation and chest compressions. In all, $6(2.4 \%)$ infants developed hypoxic ischaemic encephalopathy (HIE) (2 in stage I; 3 in stage II; 1 in stage III). Neonatal seizures occurred in $10(4.0 \%)$ infants -6 seizure episodes were caused by hypoglycaemia, 3 were due to HIE and 1 was caused by hypocalcaemia (Table III).

Among the 253 liveborn twin infants, 16 (6.3\%) passed meconium in utero. Of these 16 infants, one developed meconium aspiration syndrome (MAS). Hyaline membrane disease (HMD) developed in 31 (12.3\%) live-born infants, while 2 (0.8\%) had transient tachypnoea of newborn (TTNB). Pathological neonatal hyperbilirubinaemia (NNH) was seen in $69(27.3 \%)$ infants - 56 infants received phototherapy alone, while 13 required phototherapy and exchange blood transfusion. Hypoglycaemia (blood sugar $<40 \mathrm{mg} / \mathrm{dL}$ ) was documented in 66 (26.1\%) infants 20 infants were asymptomatic and 46 were symptomatic. Neonatal sepsis was diagnosed in 53 (20.9\%) infants - 6 infants were positive on blood culture and 18 had coexisting meningitis, which was diagnosed on cerebrospinal fluid analysis. In all, 3 (1.2\%) infants developed necrotising enterocolitis (NEC). About one-fourth of the infants died in the early neonatal period (68/253, 26.9\%) (Table III).

In the analysis of the relationship between neonatal morbidities and the many variables identified, 120 twin pairs were included. We excluded 13 twin pairs (in whom either antepartum death or gross congenital anomaly in one or both twins was seen) from this analysis given the possibility of antepartum death or gross congenital anomaly in one twin itself adversely affecting the outcome of its co-twin. The results of Pearson's chi-square test and Fisher's exact test are shown in Tables IV and V. Where two or more factors were found to influence adverse neonatal outcome, logistic regression analysis was performed to determine independent risk factors.

The principal findings of our analysis are as follows:

(1) ENNM was associated with a shorter gestational period $(p<0.01)$ and lower birth weight $(p<0.01)$. Both of these variables were confirmed as independent risk factors for ENNM on logistic regression analysis $(p<0.001)$.

(2) The incidence of low Apgar scores $(<7)$ at 1 and 5 mins of life and the need for active resuscitation at birth were higher for infants with lower gestational age $(p<0.01)$ and lower birth weight $(p<0.01)$. However, only the period of gestation was an independent risk factor on logistic regression analysis (Apgar scores $<7$ at $1 \mathrm{~min}, \mathrm{p}=0.003$; Apgar scores $<7$ at 5 mins, $p=0.001$; active resuscitation, $\mathrm{p}<0.001)$.

(3) Neonatal seizures were more frequent in infants born with non-cephalic fetal presentation at birth than those with cephalic fetal presentation $(p=0.02)$.

(4) The incidence of HMD was associated with a shorter
Table III. Morbidity and mortality profile of live-born twin infants (n = 253).

\begin{tabular}{lc}
\hline Variable & No. (\%) \\
\hline Apgar score <7 & $20(7.9)$ \\
At 1 min & $11(4.3)$ \\
At 5 mins & $30(11.9)$ \\
Requirement of active resuscitation measures* & $6(2.4)$ \\
Hypoxic ischaemic encephalopathy & $10(4.0)$ \\
Neonatal seizure & $16(6.3)$ \\
Meconium passage in utero & $1(0.4)$ \\
Meconium aspiration syndrome & $31(12.3)$ \\
Hyaline membrane disease & $2(0.8)$ \\
Transient tachypnoea of newborn & $69(27.3)$ \\
Neonatal hyperbilirubinaemia & \\
Hypoglycaemia & \\
Neonatal sepsis & $66(26.1)$ \\
Necrotising enterocolitis & $53(20.9)$ \\
Neonatal deaths (early neonatal period) & $3(1.2)$ \\
\hline
\end{tabular}

* Resuscitation measures required in the form of positive pressure ventilation with/without chest compression with/without medications. ${ }^{\dagger}$ Pathological range neonatal hyperbilirubinaemia requiring phototherapy with/without exchange blood transfusion. ₹Symptomatic/asymptomatic hypoglycaemia (blood sugar $<40 \mathrm{mg} / \mathrm{dL}$ ).

gestational period $(p<0.01)$, lower birth weight $(p<0.01)$, vaginal delivery $(p=0.02)$ and absence of IUGR $(p=0.01)$. However, logistic regression analysis found that only the period of gestation $(p=0.001)$ and birth weight were independent risk factors for HMD ( $p=0.010)$.

(5) In utero passage of meconium (meconium staining of amniotic fluid) was more common in infants with higher gestational age at birth and in the presence of IUGR $(p<0.05)$. However, only the period of gestation was an independent risk factor for meconium in utero on logistic regression analysis $(p=0.005)$.

(6) $\mathrm{NNH}$ was more frequent in infants with a shorter gestational period $(p=0.01)$.

(7) Hypoglycaemia and sepsis both developed more frequently in infants with a shorter gestational period $(p<0.01)$ and lower birth weight $(p<0.01)$. However, on logistic regression analysis, only the period of gestation was found to be an independent risk factor for hypoglycaemia $(p<0.001)$.

The association between increased inter-twin delivery time interval and adverse outcomes in the second twin was studied among the 89 vaginally delivered twin pairs. As shown in Table VI, the risk for adverse outcomes was found to be comparable in both twins, irrespective of whether the inter-twin delivery time interval was $\leq 15$ mins or $\geq 16$ mins $(p \geq 0.05)$.

\section{DISCUSSION}

The incidence of twinning is known to be influenced by factors such as race, heredity, high maternal age and parity, ovulation induction therapy and assisted-reproduction techniques. ${ }^{(1,2)}$ Available data suggests that twinning rates are highest in Nigeria (54/1,000 births) and lowest in Japan (4.3/1,000 births). ${ }^{(1,2)}$ The 
Table IV. Factors affecting adverse neonatal outcome in twin infants $(n=120)$ * $^{*}$

\begin{tabular}{|c|c|c|c|c|c|c|c|c|c|c|c|c|c|c|}
\hline \multirow[t]{3}{*}{ Variable } & \multicolumn{14}{|c|}{ Frequency of morbidities } \\
\hline & \multicolumn{2}{|c|}{$\begin{array}{c}\text { Early } \\
\text { neonatal } \\
\text { mortality }\end{array}$} & \multicolumn{2}{|c|}{$\begin{array}{l}\text { Low Apgar } \\
\text { score at } \\
1 \mathrm{~min}\end{array}$} & \multicolumn{2}{|c|}{$\begin{array}{l}\text { Low Apgar } \\
\text { score at } \\
5 \text { mins }\end{array}$} & \multicolumn{2}{|c|}{ 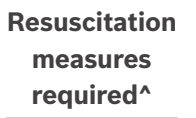 } & \multicolumn{2}{|c|}{$\begin{array}{c}\text { Hypoxic } \\
\text { ischaemic } \\
\text { encephalopathy }\end{array}$} & \multicolumn{2}{|c|}{$\begin{array}{l}\text { Neonatal } \\
\text { seizures }\end{array}$} & \multicolumn{2}{|c|}{$\begin{array}{c}\text { Hyaline } \\
\text { membrane } \\
\text { disease }\end{array}$} \\
\hline & No. & p-value ${ }^{+}$ & No. & p-value ${ }^{+}$ & No. & p-value ${ }^{+}$ & No. & p-value ${ }^{+}$ & No. & p-value $^{+}$ & No. & p-value ${ }^{+}$ & No. & p-value ${ }^{+}$ \\
\hline $\begin{array}{l}\text { Chorionicity of } \\
\text { gestation }\end{array}$ & & 0.57 & & 0.87 & & 0.87 & & 0.59 & & 1.00 & & 0.88 & & 0.43 \\
\hline Monochorionic $(n=28)$ & 6 & & 2 & & 1 & & 4 & & 0 & & 1 & & 2 & \\
\hline Dichorionic $(n=212)$ & 56 & & 17 & & 9 & & 23 & & 6 & & 9 & & 26 & \\
\hline $\begin{array}{l}\text { Period of } \\
\text { gestation (wks) }\end{array}$ & & $<0.01^{*}$ & & $<0.01^{*}$ & & $<0.01^{*}$ & & $<0.01^{*}$ & & 0.37 & & 0.81 & & $<0.01^{\ddagger}$ \\
\hline$\leq 33(n=40)$ & 35 & & 9 & & 7 & & 12 & & 2 & & 1 & & 26 & \\
\hline $34-36(n=98)$ & 22 & & 6 & & 1 & & 10 & & 1 & & 4 & & 2 & \\
\hline $\begin{array}{l}\text { Fetal presentation at } \\
\text { birth }\end{array}$ & & 0.27 & & 0.08 & & 0.71 & & 0.17 & & 0.42 & & $0.02^{\ddagger}$ & & 0.77 \\
\hline Non-cephalic $(n=83)$ & 25 & & 10 & & 4 & & 13 & & 3 & & 7 & & 9 & \\
\hline Cephalic $(n=157)$ & 37 & & 9 & & 6 & & 14 & & 3 & & 3 & & 19 & \\
\hline Route of delivery & & 0.50 & & 0.96 & & 0.24 & & 0.63 & & 1.00 & & 0.76 & & $0.02^{\ddagger}$ \\
\hline Vaginal $(n=178)$ & 48 & & 14 & & 9 & & 19 & & 5 & & 7 & & 26 & \\
\hline $\begin{array}{l}\text { Caesarean section } \\
(n=62)\end{array}$ & 14 & & 5 & & 1 & & 8 & & 1 & & 3 & & 2 & \\
\hline Birth order & & 0.08 & & 0.47 & & 1.00 & & 0.54 & & 0.10 & & 0.20 & & 1.00 \\
\hline First twin $(n=120)$ & 25 & & 8 & & 5 & & 12 & & 1 & & 3 & & 14 & \\
\hline Second twin $(n=120)$ & 37 & & 11 & & 5 & & 15 & & 5 & & 7 & & 14 & \\
\hline Gender & & 0.50 & & 0.22 & & 0.50 & & 0.29 & & 1.00 & & 0.54 & & 0.25 \\
\hline Birth weight (g) & & $<0.01^{*}$ & & $<0.01^{*}$ & & $<0.01^{*}$ & & $<0.01^{*}$ & & 0.46 & & $<0.10$ & & $<0.01^{\ddagger}$ \\
\hline$<1,500(n=44)$ & 40 & & 9 & & 6 & & 11 & & 2 & & 0 & & 26 & \\
\hline $1,500-2,499(n=166)$ & 22 & & 9 & & 4 & & 14 & & 4 & & 10 & & 2 & \\
\hline$\geq 2,500(n=30)$ & 0 & & 1 & & 0 & & 2 & & 0 & & 0 & & 0 & \\
\hline $\begin{array}{l}\text { Birth weight } \\
\text { discordance }\end{array}$ & & 0.73 & & 0.43 & & 0.75 & & 0.48 & & 0.34 & & 0.07 & & 0.72 \\
\hline$<20 \%(n=182)$ & 46 & & 13 & & 8 & & 19 & & 6 & & 10 & & 22 & \\
\hline$\geq 20 \%(n=58)$ & 16 & & 6 & & 2 & & 8 & & 0 & & 0 & & 6 & \\
\hline $\begin{array}{l}\text { Intrauterine growth } \\
\text { restriction }\end{array}$ & & 0.67 & & 0.89 & & 0.79 & & 0.17 & & 1.00 & & 0.79 & & $0.01^{*}$ \\
\hline No $(n=130)$ & 35 & & 10 & & 5 & & 18 & & 3 & & 5 & & 22 & \\
\hline Yes $(n=110)$ & 27 & & 9 & & 5 & & 9 & & 3 & & 5 & & 6 & \\
\hline
\end{tabular}

*13 twin pairs with antepartum death or gross congenital anomaly in one/both twins were excluded from the analysis. 'Pearson's chi-square test and Fisher's exact test. ${ }^{*} \mathrm{p}<0.05$ was considered statistically significant. ${ }^{\wedge}$ Resuscitation measures required in the form of positive pressure ventilation with/without chest compression with/without medications.

twinning rate in Singapore in the period 1998-2001, according to the national registry of births and deaths, was around 1 in 105 pregnancies (9.5/1,000 births). ${ }^{(36)}$ Various old and new datasets from India report twinning rates ranging from 1 in $88^{(1,2)}$ to 1 in $138^{(37)}$ pregnancies, which are comparable to the findings from Singapore. ${ }^{(36)}$ In the present study, a higher frequency of twinning ( 1 in 54 pregnancies) was observed when compared to earlier reports from India. ${ }^{(1,2,37)}$ As our study was conducted at a tertiary hospital, it is possible that this variation was a result of referral bias for high-risk pregnancies to our centre. Also, many studies in the literature that reported twinning rates have included only live births in their analyses while excluding stillbirths, which may have influenced the conclusions drawn. The estimated dizygotic-to-monozygotic twin ratio was 0.69:1.00 in Singapore, ${ }^{(36)}$ which was low compared to our finding of 2.8:1.0. This may indicate a higher proportion of monozygotic twin births in Singapore. In our study, $10 \%$ of mothers had some predisposition for twinning due to either familial history or the consumption of clomiphene for the treatment of infertility.

Twin pregnancies are associated with a high risk of maternal complications. Physiological anaemia is more pronounced in 
Table V. Factors affecting adverse neonatal outcome in twin infants $(n=120) .^{*}$

\begin{tabular}{|c|c|c|c|c|c|c|c|c|c|c|c|c|c|c|}
\hline \multirow[t]{3}{*}{ Variable } & \multicolumn{14}{|c|}{ Frequency of morbidities } \\
\hline & \multicolumn{2}{|c|}{$\begin{array}{c}\text { Transient } \\
\text { tachypnoea } \\
\text { of newborn }\end{array}$} & \multicolumn{2}{|c|}{$\begin{array}{l}\text { Meconium } \\
\text { staining of } \\
\text { amniotic } \\
\text { fluid }\end{array}$} & \multicolumn{2}{|c|}{$\begin{array}{l}\text { Meconium } \\
\text { aspiration } \\
\text { syndrome }\end{array}$} & \multicolumn{2}{|c|}{ 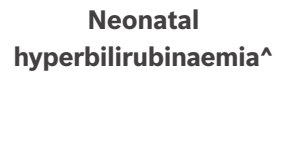 } & \multicolumn{2}{|c|}{ Hypoglycaemia" } & \multicolumn{2}{|c|}{ Sepsis } & \multicolumn{2}{|c|}{$\begin{array}{l}\text { Necrotising } \\
\text { enterocolitis }\end{array}$} \\
\hline & No. & p-value ${ }^{+}$ & No. & p-value ${ }^{+}$ & No. & p-value ${ }^{+}$ & No. & p-value ${ }^{+}$ & No. & p-value ${ }^{+}$ & No. & p-value ${ }^{+}$ & No. & p-value ${ }^{+}$ \\
\hline $\begin{array}{l}\text { Chorionicity of } \\
\text { gestation }\end{array}$ & & 1.00 & & 0.48 & & 1.00 & & 0.47 & & 0.79 & & 0.34 & & 1.00 \\
\hline Monochorionic $(n=28)$ & 0 & & 1 & & 0 & & 6 & & 7 & & 4 & & 0 & \\
\hline Dichorionic $(n=212)$ & 2 & & 15 & & 1 & & 59 & & 58 & & 47 & & 3 & \\
\hline $\begin{array}{l}\text { Period of } \\
\text { gestation (wks) }\end{array}$ & & 0.26 & & $<0.01^{\ddagger}$ & & 0.51 & & $0.01^{\ddagger}$ & & $<0.01^{\ddagger}$ & & $<0.01^{*}$ & & 0.11 \\
\hline$\leq 33(n=40)$ & 0 & & 0 & & 0 & & 15 & & 19 & & 21 & & 0 & \\
\hline $34-36(n=98)$ & 0 & & 1 & & 0 & & 32 & & 34 & & 25 & & 3 & \\
\hline$\geq 37(n=102)$ & 2 & & 15 & & 1 & & 18 & & 12 & & 5 & & 0 & \\
\hline $\begin{array}{l}\text { Fetal presentation at } \\
\text { birth }\end{array}$ & & 0.18 & & 0.05 & & 0.35 & & 0.64 & & 0.64 & & 0.65 & & 0.27 \\
\hline Non-cephalic $(n=83)$ & 2 & & 2 & & 1 & & 24 & & 24 & & 19 & & 2 & \\
\hline Cephalic $(n=157)$ & 0 & & 14 & & 0 & & 41 & & 41 & & 32 & & 1 & \\
\hline Route of delivery & & 0.07 & & 0.09 & & 0.26 & & 0.69 & & 0.79 & & 0.51 & & 0.57 \\
\hline Vaginal $(n=178)$ & 0 & & 9 & & 0 & & 47 & & 49 & & 36 & & 3 & \\
\hline $\begin{array}{l}\text { Caesarean section } \\
(n=62)\end{array}$ & 2 & & 7 & & 1 & & 18 & & 16 & & 15 & & 0 & \\
\hline Birth order & & 1.00 & & 1.00 & & 1.00 & & 0.88 & & 0.31 & & 0.16 & & 1.00 \\
\hline First twin $(n=120)$ & 1 & & 8 & & 0 & & 32 & & 29 & & 21 & & 1 & \\
\hline Second twin $(n=120)$ & 1 & & 8 & & 1 & & 33 & & 36 & & 30 & & 2 & \\
\hline Gender & & 1.00 & & 0.97 & & 0.50 & & 0.61 & & 0.95 & & 0.82 & & 0.25 \\
\hline Female $(n=119)$ & 1 & & 8 & & 1 & & 34 & & 32 & & 26 & & 0 & \\
\hline Birth weight (g) & & 0.25 & & 0.13 & & 0.80 & & 0.19 & & $<0.01^{*}$ & & $<0.01^{\ddagger}$ & & 0.68 \\
\hline$<1,500(n=44)$ & 0 & & 0 & & 0 & & 13 & & 22 & & 24 & & 1 & \\
\hline $1,500-2,499(n=166)$ & 1 & & 13 & & 1 & & 48 & & 40 & & 26 & & 2 & \\
\hline$\geq 2,500(n=30)$ & 1 & & 3 & & 0 & & 4 & & 3 & & 1 & & 0 & \\
\hline $\begin{array}{l}\text { Birth weight } \\
\text { discordance }\end{array}$ & & 1.00 & & 0.26 & & 1.00 & & 0.21 & & 0.44 & & 0.08 & & 0.15 \\
\hline$<20 \%(n=182)$ & 2 & & 14 & & 1 & & 53 & & 47 & & 34 & & 1 & \\
\hline$\geq 20 \%(n=58)$ & 0 & & 2 & & 0 & & 12 & & 18 & & 17 & & 2 & \\
\hline $\begin{array}{l}\text { Intrauterine growth } \\
\text { restriction }\end{array}$ & & 0.21 & & $0.01^{*}$ & & 0.46 & & 0.05 & & 0.52 & & 0.28 & & 1.00 \\
\hline No $(n=130)$ & 0 & & 4 & & 0 & & 42 & & 33 & & 31 & & 2 & \\
\hline Yes $(n=110)$ & 2 & & 12 & & 1 & & 23 & & 32 & & 20 & & 1 & \\
\hline
\end{tabular}

*13 twin pairs with antepartum death or gross congenital anomaly in one/both twins were excluded from the analysis. ${ }^{\dagger}$ Pearson's chi-square test and Fisher's exact test. ${ }^{\ddagger} p<0.05$ was considered statistically significant. ${ }^{\wedge}$ Pathological range neonatal hyperbilirubinaemia requiring phototherapy with/without exchange blood transfusion. "Symptomatic/asymptomatic hypoglycaemia (blood sugar $<40 \mathrm{mg} / \mathrm{dL}$ ).

twin gestations, with a reported prevalence of $2.4 \%-8.0 \%$ in studies from overseas centres. ${ }^{(1,3,38,39)}$ Gestational hypertension is also very common, with overall prevalence in twin gestations reported at $9 \%-20 \% .{ }^{(1,3,38,39)}$ Moreover, there is a high risk of antepartum haemorrhage in twin gestations due to the higher incidence of placenta praevia, ${ }^{(40)}$ with an approximately threefold increase in the frequency of abruption. ${ }^{(41)}$ The reported incidence of antepartum haemorrhage in mothers carrying twins is $0.3 \%-0.7 \% .^{(3,38)}$ It has been reported that polyhydramnios occurs in $0.3 \%$ of twin gestations, and prelabour rupture of the membranes in around $1.5 \%$ of cases. ${ }^{(38)}$
In the current study, we found a high incidence of maternal morbidities, with maternal anaemia $(85.0 \%)$ being the most common, followed by gestational hypertension (17.3\%). The prevalence of gestational hypertension in our study is congruent with that reported in the literature $(9 \%-20 \%) .(1,3,38,39)$ The incidence of preeclampsia in twin gestations (18/133, 13.5\%) in our cohort, however, was nearly twice that reported in the Singapore cohort $(7.5 \%)$ by Tan et al. ${ }^{(42)}$ Similarly, the prevalence of maternal anaemia was quite high in our study, which may reflect a generally high baseline prevalence of maternal anaemia in India ${ }^{(43)}$ that is further amplified by twin pregnancies. 
Table VI. Inter-twin delivery time interval and neonatal outcome in twins.

\begin{tabular}{|c|c|c|c|c|c|c|c|c|c|c|c|c|}
\hline \multirow{4}{*}{$\begin{array}{l}\text { Adverse neonatal } \\
\text { outcome }\end{array}$} & \multicolumn{12}{|c|}{ Inter-twin delivery time interval } \\
\hline & \multicolumn{6}{|c|}{ All live-born twin pairs $(n=120)^{*}$} & \multicolumn{6}{|c|}{ Vaginally delivered live-born twin pairs $(n=89)^{* *}$} \\
\hline & \multicolumn{3}{|c|}{$\leq 15$ mins $(n=95)$} & \multicolumn{3}{|c|}{$\geq 16$ mins $(n=25)$} & \multicolumn{3}{|c|}{$\leq 15$ mins $(n=65)$} & \multicolumn{3}{|c|}{$\geq 16$ mins $(n=24)$} \\
\hline & 1st twin & 2nd twin & p-value ${ }^{+}$ & 1st twin & 2nd twin & p-value ${ }^{+}$ & 1st twin & 2nd twin & p-value ${ }^{+}$ & 1st twin & 2nd twin & p-value ${ }^{+}$ \\
\hline $\begin{array}{l}\text { Early neonatal } \\
\text { mortality }\end{array}$ & 20 & 30 & 0.14 & 5 & 7 & 0.74 & 16 & 20 & 0.56 & 5 & 7 & 0.74 \\
\hline $\begin{array}{l}\text { Low Apgar score at } \\
5 \text { mins }\end{array}$ & 5 & 3 & 0.72 & 0 & 2 & 0.47 & 4 & 3 & 1.00 & 0 & 2 & 0.47 \\
\hline $\begin{array}{l}\text { Resuscitation } \\
\text { measures required^}\end{array}$ & 12 & 13 & 1.00 & 0 & 2 & 0.47 & 7 & 10 & 0.60 & 0 & 2 & 0.47 \\
\hline $\begin{array}{l}\text { Hypoxic ischaemic } \\
\text { encephalopathy }\end{array}$ & 1 & 3 & 0.61 & 0 & 2 & 0.47 & 1 & 2 & 1.00 & 0 & 2 & 0.47 \\
\hline Neonatal seizure & 3 & 4 & 1.00 & 0 & 3 & 0.23 & 1 & 3 & 1.61 & 0 & 3 & 0.23 \\
\hline $\begin{array}{l}\text { Hyaline membrane } \\
\text { disease }\end{array}$ & 12 & 12 & 1.00 & 2 & 2 & 1.00 & 11 & 11 & 1.00 & 2 & 2 & 1.00 \\
\hline $\begin{array}{l}\text { Transient tachypnoea } \\
\text { of newborn }\end{array}$ & 1 & 1 & 1.00 & 0 & 0 & - & 0 & 0 & - & 0 & 0 & - \\
\hline $\begin{array}{l}\text { Meconium staining } \\
\text { of amniotic fluid }\end{array}$ & 4 & 5 & 1.00 & 4 & 3 & 1.00 & 1 & 3 & 0.61 & 3 & 2 & 1.00 \\
\hline $\begin{array}{l}\text { Meconium aspiration } \\
\text { syndrome }\end{array}$ & 0 & 1 & 1.00 & 0 & 0 & - & 0 & 0 & - & 0 & 0 & - \\
\hline $\begin{array}{l}\text { Neonatal } \\
\text { hyperbilirubinaemia }^{*}\end{array}$ & 30 & 27 & 0.75 & 2 & 6 & 0.25 & 21 & 18 & 0.70 & 2 & 6 & 0.24 \\
\hline Hypoglycaemia" & 24 & 27 & 0.74 & 5 & 9 & 0.34 & 16 & 20 & 0.56 & 5 & 8 & 0.52 \\
\hline Sepsis & 17 & 24 & 0.29 & 4 & 6 & 0.72 & 12 & 15 & 0.66 & 4 & 5 & 1.00 \\
\hline
\end{tabular}

*13 twin pairs with antepartum death or gross congenital anomaly in one/both twins were excluded from the analysis. ** 89 vaginally delivered pairs in which both twins were live-born and none had gross congenital anomaly. ${ }^{+}$Pearson’s chi-square test and Fisher’s exact test. ${ }^{\ddagger} p<0.05$ was considered statistically significant. ${ }^{\wedge}$ Resuscitation measures required in the form of positive pressure ventilation with/without chest compression with/without medications. *Pathological range neonatal hyperbilirubinaemia requiring phototherapy with/without exchange blood transfusion. "Symptomatic/asymptomatic hypoglycaemia (blood sugar < $40 \mathrm{mg} / \mathrm{dL}$ ).

Various studies have reported significantly higher rates of Caesarean sections in twin pregnancies compared to singleton pregnancy, with a $20 \%-76 \%$ incidence of Caesarean sections in twin pregnancies being reported..$^{(3,5,7-9)}$ Most reviews recommend that Caesarean sections always be performed when the first twin has a breech presentation. ${ }^{(1,10)}$ It has also been suggested that when the first twin has a cephalic presentation, vaginal delivery should always be attempted irrespective of the lie and presentation of the second twin. ${ }^{(1,10)}$ Such strategies are based on observations that the presentation of the second twin may change following the delivery of the first twin. However, attempting to deliver the second twin vaginally after the delivery of the first twin may occasionally be unwise or impossible; in these women, prompt Caesarean section is recommended..$^{(1,10)}$ In our study, about $28 \%$ of mothers delivered by Caesarean section, and the most common indication for such delivery was breech first twin, similar to previous studies. ${ }^{(3)}$

All possible combinations of fetal positions may be encountered in twin pregnancies. However, presentations other than cephaliccephalic are deemed unstable prior to and during labour or delivery. ${ }^{(1)}$ In our study, cephalic-cephalic presentation was the most common (48.9\%) and 38.3\% of twin pairs were unlike-sexed, similar to a study by Mutihir and Pam. ${ }^{(5)}$ In like manner, premature birth is more widely known to occur in twin pregnancies than singleton pregnancies, with the reported risk at $33 \%-62 \% .^{(1,6,7-9)}$ Thus, preterm labour is the most common complication of multiple gestations. ${ }^{(3,38)}$ In our study, about $61 \%$ of twin deliveries were preterm and the mean period of gestation at birth was 35 weeks.

Mortality in twins is six-fold that of singletons, which is mainly attributable to the high incidence of prematurity and low birth weight in twins ${ }^{(6,7)}$ Other reported risk factors for perinatal mortality in twins include monochorionicity, ${ }^{(11)}$ vaginal route of delivery, ${ }^{(7,12)}$ second birth order, ${ }^{(7,9,12,15)}$ male gender, ${ }^{(14)}$ high BWD ${ }^{(13)}$ and IUGR. ${ }^{(13)}$ Conversely, some studies have reported no significant relationship between perinatal mortality in twins and the route of delivery, ${ }^{(6)}$ birth order $^{(16,17)}$ and gender. ${ }^{(6)}$ In our study, ENNM was observed in about $27 \%$ of live-born twin infants, and this was mainly attributable to prematurity and low birth weight. The rates for stillbirth and perinatal mortality (using $\geq 23$ weeks of gestation as the minimum gestation for viability) among twins in our study were 48.9 per 1,000 births (13/266) and 320.1 per 1,000 live births (81/253), respectively. In contrast, studies on twins from developed countries report stillbirth rates of 28-74 per 1,000 births ${ }^{(6-9)}$ and perinatal loss of 54-152 per 1,000 live births. ${ }^{(6-9)}$ Perinatal mortality rates in our study were thus elevated when compared to reports from the literature. 
Moreover, twins are more prone to birth asphyxia than singletons, which is largely attributed to the higher rate of prematurity in twins. ${ }^{(6,18)}$ Various studies have also suggested that the second twin is more prone to perinatal asphyxia. ${ }^{(8,12,20,38)}$ Abnormal (non-cephalic) presentation ${ }^{(7)}$ and the vaginal route of delivery have been described as risk factors for birth asphyxia. ${ }^{(12,21)}$ Apgar scores $<7$ at 1 and 5 mins have been found in 13\%-32\% and $2 \%-12 \%$ of twins, respectively, ${ }^{(9,19)}$ just as active resuscitation measures are said to be required in nearly $30 \%$ of twins. ${ }^{(9)}$ In our study, the incidence of low Apgar scores (score $<7$ ) at $1 \mathrm{~min}$ and 5 mins of life was around $8 \%$ and $4 \%$, respectively. Nearly $12 \%$ of our infants required some active resuscitation at birth. Regression analysis indicated that prematurity was the only independent risk factor in our cohort. The incidence of HIE in our cohort was about $2 \%$.

It is generally accepted that the time interval between the deliveries of the two twins should be within 15 mins and not more than 30 mins, so as to minimise hypoxia in the second twin. (22) However, a study by Rydhström and Ingemarsson suggested that higher perinatal morbidity and mortality associated with long delays between the deliveries of the two twins were not apparent when continuous fetal heart rate monitoring was employed.(23) Although longer inter-twin delivery time intervals are associated with a slow decline in the $\mathrm{pH}$ of umbilical blood, such small variations in $\mathrm{pH}$ would not sufficiently alter the clinical management of the twins. ${ }^{(24)}$ In our study, morbidity, including low Apgar scores and/or ENNM, was not affected in spite of the inter-twin delivery time intervals being as wide as 60 mins.

According to Ghai and Vidyasagar, twins have a higher incidence of neonatal seizures than singletons, but there is no difference in the incidence of neonatal seizures between the first and second twins or between genders. ${ }^{(6)}$ Nassar et al reported a $1 \%$ incidence of neonatal seizures in twins, ${ }^{(25)}$ and Hollier et al found higher BWD to be a risk factor for neonatal seizures. ${ }^{(26)}$ In our study, seizures were seen in about $4 \%$ of twin infants, and the most common aetiology was hypoglycaemia, followed by HIE and hypocalcaemia. Also, twins with non-cephalic presentation at birth had a higher risk of neonatal seizures than those with cephalic presentation. However, other factors, including BWD, were not found to affect the risk for neonatal seizures.

The incidence of HMD in twins has been reported to be about $10 \%-40 \% .^{(6-8,25)}$ Respiratory morbidities other than HMD, such as TTNB and MAS, are also strikingly elevated in twins. ${ }^{(6)}$ Male gender is known to be associated with a higher risk of HMD, ${ }^{(27)}$ although some studies disagree. ${ }^{(6)}$ Similarly, second-born twins have been found to have a higher risk of HMD, a finding probably related to the higher incidence of birth asphyxia and low Apgar scores in these infants. ${ }^{(15,17)}$ However, some authors have found no difference in the incidence of HMD between the first and second twins. ${ }^{(6,7)}$ Hollier et al have shown that higher BWD was a risk factor for $\mathrm{HMD},{ }^{(26)}$ although Nassar et al did not find any such association. (25) HMD was observed in about $12 \%$ of twin infants in our study, and only prematurity and lower birth weight were identified as independent risk factors.
Studies suggest that pathological $\mathrm{NNH}$ occurs in nearly one-third of twin infants, ${ }^{(9,25)}$ although this increased risk of $\mathrm{NNH}$ in twins is mainly attributed to prematurity rather than twinning per se. ${ }^{(7,28)}$ The risk of $\mathrm{NNH}$ in the first and second twins is reported to be comparable. ${ }^{(7,28)}$ Cohen et al demonstrated that BWD was a risk factor for $\mathrm{NNH}^{(29)}$ In our study, the incidence of pathological $\mathrm{NNH}$ was about $27 \%$, and the risk was only associated with lower gestational age at birth.

Ho and $\mathrm{Wu}^{\left({ }^{(7)}\right.}$ and Eskes et $\mathrm{al}^{\left({ }^{(9)}\right.}$ found that nearly $10 \%$ of all twin infants had episode(s) of hypoglycaemia. Fraser et al found that higher BWD was associated with a higher risk for hypoglycaemia. ${ }^{(13)}$ In our study, hypoglycaemia (blood sugar $<40 \mathrm{mg} / \mathrm{dL}$ ) was detected in about $26 \%$ of twin infants at least once during the early neonatal period. It is likely that the higher incidence of hypoglycaemia noted in our study was related to the longer periods of observation when compared to previous studies. Only prematurity was identified as an independent risk factor for hypoglycaemia on regression analysis.

Twin infants are at a high risk for neonatal sepsis, with a reported incidence of $2 \%-6 \% .^{(9,25)}$ Risk for neonatal sepsis increases with higher BWD, ${ }^{(26,30)}$ although some studies have found otherwise. ${ }^{(25)}$ We found early onset neonatal sepsis in about $21 \%$ of infants, which is much higher than the overall incidence of clinical sepsis (2.5\%) reported by Gupta et al from the same neonatal intensive care unit.(44) Only shorter gestation periods were identified as a risk factor for neonatal sepsis in our study.

The reported incidence of NEC in twins was $0.9 \%-4 \%{ }^{(8,25)}$ According to Wiswell and Hankins, the higher risk for birth asphyxia and hypoxia in the second twin is important in the pathogenesis of NEC in these infants, ${ }^{(31)}$ although Samm et al's study suggests otherwise. ${ }^{(32)}$ Hollier et al $^{(26)}$ found higher BWD to be a risk factor for NEC in twins, but Nassar et al found no such association. ${ }^{(25)}$ The incidence of NEC among twin infants in our study was about $1 \%$, and none of the assessed factors were found to be associated with the risk for NEC.

To summarise, the high incidence of maternal and neonatal morbidities seen among twins in our study is in agreement with the findings of previous studies, suggesting that multiple gestations are associated with worse outcome than singleton pregnancies. Although twins account far only a small percentage of live births, they are associated with a disproportionately higher mortality rate. One of the strengths of the present study was its prospective design, which allowed for accurate documentation of all morbidities in twins. However, a disadvantage was that the findings in twins were not compared against gestational age-matched singleton infants as control. Further extensive regional multicentric studies with larger sample sizes are thus warranted in order to establish the associations seen in our study.

\section{REFERENCES}

1. Cunningham FG, Leveno KJ, Bloom SL, et al. Multifetal gestation. In: Cunningham FG, Leveno KJ, Bloom SL, et al, eds. Williams Obstetrics, 22nd ed. New York: McGraw-Hill, 2005: 911-948.

2. MacGillivray I. Epidemiology of twin pregnancy. Semin Perinatol 1986; 10:4-8.

3. Isiaka-lawal S, Adesina KT, Saidu R, et al. A review of twin gestation in a tertiary health institution in nNorth Central Nigeria. Res J Med Sci 2009; 3:198-201. 
4. Satija M, Sharma S, Soni RK, Sachar RK, Singh GP. Twinning and its correlates: community-based study in a rural area of India. Hum Biol 2008; 80:611-21.

5. Mutihir JT, Pam VC. Obstetric outcome of twin pregnancies in Jos, Nigeria. Niger J Clin Pract 2007; 10:15-8.

6. Ghai V, Vidyasagar D. Morbidity and mortality factors in twins. An epidemiologic approach. Clin Perinatol 1988; 15:123-40.

7. Ho SK, Wu PY. Perinatal factors and neonatal morbidity in twin pregnancy. Am J Obstet Gynecol 1975; 122:979-87.

8. Suri K, Bhandari V, Lerer T, Rosenkrantz TS, Hussain N. Morbidity and mortality of preterm twins and higher-order multiple births. J Perinatol 2001; 21:293-9.

9. Eskes TK, Timmer H, Kollée LA, Jongsma HW. The second twin. Eur J Obstet Gynecol Reprod Biol 1985; 19:159-66.

10. Breeze A, Smith G. Mode of delivery of twins. Risk Management - The Obstetrician and Gynaecologist 2004; 6:222-6.

11. Machin GA. Why is it important to diagnose chorionicity and how do we do it? Best Pract Res Clin Obstet Gynaecol 2004; 18:515-30.

12. Chen SJ, Vohr BR, Oh W. Effects of birth order, gender, and intrauterine growth retardation on the outcome of very low birth weight in twins. J Pediatr 1993; 123:132-6.

13. Fraser D, Picard R, Picard E, Leiberman JR. Birth weight discordance, intrauterine growth retardation and perinatal outcomes in twins. J Reprod Med 1994; 39:504-8.

14. Shinwell ES, Blickstein I, Lusky A, Reichman B. Effect of birth order on neonatal morbidity and mortality among very low birthweight twins: a population based study. Arch Dis Child Fetal Neonatal Ed 2004; 89:F145-8.

15. Smith GC, Fleming KM, White IR. Birth order of twins and risk of perinatal death related to delivery in England, Northern Ireland, and Wales, 1994 2003: retrospective cohort study. BMJ 2007; 334:576.

16. Haest KM, Roumen FJ, Nijhuis JG. Neonatal and maternal outcomes in twin gestations $>$ or $=32$ weeks according to the planned mode of delivery. Eur J Obstet Gynecol Reprod Biol 2005; 123:17-21.

17. Cetrulo CL. The controversy of mode of delivery in twins: the intrapartum management of twin gestation (Part 1). Semin Perinatol 1986; 10:39-43.

18. Erdemoglu E, Mungan T, Tapisiz OL, Ustunyurt E, Caglar E. Effect of intertwin delivery time on Apgar scores of the second twin. Aust N Z J Obstet Gynaecol 2003; 43:203-6.

19. Suh YH, Park KH, Hong JS, et al. Relationship between twin-to-twin delivery interval and umbilical artery acid-base status in the second twin. J Korean Med Sci 2007; 22:248-53.

20. Hartley RS, Hitti J. Birth order and delivery interval: analysis of twin pair perinatal outcomes. J Matern Fetal Neonatal Med 2005; 17:375-80.

21. Armson BA, O'Connell C, Persad V, et al. Determinants of perinata mortality and serious neonatal morbidity in the second twin. Obstet Gynecol 2006; 108:556-64.

22. Farooqui MO, Grossman JH 3rd, Shannon RA. A review of twin pregnancy and perinatal mortality. Obstet Gynecol Surv 1973; 28 Suppl:144-53.

23. Rydhström H, Ingemarsson I. Interval between birth of the first and the second twin and its impact on second twin perinatal mortality. J Perinat Med 1990; 18:449-53.
24. McGrail CD, Bryant DR. Intertwin time interval: how it affects the immediate neonatal outcome of the second twin. Am J Obstet Gynecol 2005; 192:1420-2

25. Nassar AH, Usta IM, Khalil AM, Aswad NA, Seoud MA. Neonatal outcome of growth discordant twin gestations. J Perinat Med 2003; 31:330-6.

26. Hollier LM, Mclntire DD, Leveno KJ. Outcome of twin pregnancies according to intrapair birth weight differences. Obstet Gynecol 1999; 94:1006-10

27. Collins JW, David RJ, Boehm JJ. Respiratory distress syndrome explains sex but not race differences in birth weight specific mortality. Pediatr Res 1987; $21: 393-7$

28. Tan KL. Neonatal jaundice in twins. Aust Paediatr J 1980; 16:70-2.

29. Cohen SB, Elizur SE, Goldenberg M, et al. Outcome of twin pregnancies with extreme weight discordancy. Am J Perinatol 2001; 18:427-32.

30. Tan H, Wen SW, Fung Kee Fung K, Walker M, Demissie K. The distribution of intra-twin birth weight discordance and its association with total twin birth weight, gestational age, and neonatal mortality. Eur J Obstet Gynecol Reprod Biol 2005; 121:27-33.

31. Wiswell TE, Hankins CT. Twins and triplets with necrotizing enterocolitis. Am J Dis Child 1988; 142:1004-6.

32. Samm M, Curtis-Cohen M, Keller M, Chawla H. Necrotizing enterocolitis in infants of multiple gestation. Am J Dis Child 1986; 140:937-9.

33. Ballard JL, Khoury JC, Wedig K, et al. New Ballard Score expanded to include extremely premature infants. J Pediatr 1991; 119:417-23.

34. Fenton TR. A new growth chart for preterm babies: Babson and Benda's chart updated with recent data and a new format. BMC Pediatrics 2003; 3:13.

35. Gupta P, Faridi MM, Shah D, Dev G. BCG reaction in twin newborns: Effect of zygosity and chorionicity. Indian Pediatr 2008; 45:271-7.

36. Chia KS, Lee JJ, Cheung P, et al. Twin births in Singapore: a populationbased study using the National Birth Registry. Ann Acad Med Singapore 2004; 33:195-9.

37. Smits J, Monden C. Twinning across the developing world. PLoS One 2011; 6:e25239.

38. Musili F, Karanja JG. Multifoetal pregnancies at a maternity hospital in Nairobi. East Afr Med J 2009; 86:162-5.

39. Lam H, Ho PC. Comparison of pregnancy outcome between high- order multiple and twin pregnancies: matched-pair retrospective study. Hong Kong Med J 1999; 5:16-20.

40. Benirschke K, Masliah E. The placenta in multiple pregnancy: outstanding issues. Reprod Fertil Dev 2001; 13:615-22.

41. Newman RB. Multiple gestation. In: Scott JR, Gibbs RS, Karlan BY, Haney AF, Danforth DN, eds. Danforth's Obstetrics and Gynecology. 9th ed. Philadelphia: Lippincott Williams \& Wilkins, 2003: 225-45.

42. Tan KH, Kwek K, Yeo GS. Epidemiology of pre-eclampsia and eclampsia at the KK Women's and Children's Hospital, Singapore. Singapore Med J 2006; 47:48-53.

43. National Family Health Survey (NFHS)-3. IIPS, Mumbai 2005-2006. Ministry of Health \& Family Welfare, Govt. of India.

44. Gupta P, Murali MV, Faridi MM, et al. Clinical profile of klebsiella septicemia in neonates. Indian J Pediatr 1993; 60:565-72. 